\title{
Comparison of retinal nerve fiber layer measurements using Stratus OCT fast and regular scan protocols in eyes with band atrophy of the optic nerve and normal controls
}

\author{
Comparação das medidas da camada de fibras nervosas retinianas realizadas \\ com os protocolos "fast" e "regular" do Stratus OCT em olhos com atrofia \\ em banda do nervo óptico e controles normais
}

\author{
Mário Luiz Ribeiro Monteiro \\ Leonardo Provetti Cunha ${ }^{2}$ \\ Roberto Murad Vessani ${ }^{3}$
}

Trabalho realizado no Departamento de Oftalmologia da Universidade de São Paulo - USP.

Associate Professor of Ophthalmology and Chief of the Neuro-ophthalmology and Orbital Diseases Services, Division of Ophthalmology of the University of São Paulo Medical School.

${ }^{2}$ Post-graduate Student, Neuro-ophthalmology Service, Division of Ophthalmology of the University of São Paulo Medical School.

${ }^{3}$ Post-graduate Student, Glaucoma Service, Division of Ophthalmology of the University of São Paulo Medical School.

Corresponding author: Mário L. R. Monteiro. Av. Angélica, 1757 - Conj. 61 - São Paulo (SP)

CEP 01227-200

E-mail: mlrmonteiro@ terra.com.br

Recebido para publicação em 02.10.2007

Última versão recebida em 06.02.2008

Aprovação em 16.03.2008

Supported by a grant from Fundação de Amparo a Pesquisa do Estado de São Paulo FAPESP (№ 07/54142-0) São Paulo - Brazil.

\begin{tabular}{|l|}
\hline ABSTRACT \\
\hline Purpose: To compare retinal nerve fiber layer (RNFL) measurements \\
made with two different protocols of optical coherence tomography in \\
eyes with band atrophy (BA) of the optic nerve and controls. Methods: \\
Twenty-nine eyes with BA from chiasmal compression and 30 normal \\
eyes underwent RNFL scans using both the fast (256 A-scans) and the \\
regular (512 A-scans) protocols. The two sets of measurements were \\
compared. Results: In eyes with BA, fast RNFL measurements were \\
significantly greater compared with regular RNFL measurements in the \\
superior and inferior quadrants and significantly smaller at the 30 -degree \\
segments located at the 3 and 6 o'clock meridians. In normal eyes, fast \\
RNFL measurements of the total average, superior and inferior quadrants \\
and the segments corresponding to the 1, 3, 4 and 12 o'clock meridians \\
were significantly greater than regular protocol measurements. Measu- \\
rements with both protocols were significantly different in eyes with BA \\
compared to normal eyes. Conclusions: Although both fast and regular \\
RNFL measurements were equally efficient at differentiating eyes with \\
BA from controls the fast protocol yielded greater values in areas with \\
thick RNFL and smaller values in areas with thin RNFL when compared \\
with the regular scanning protocol. One should be aware of such diffe- \\
rences when comparing measurements with both scanning protocols. \\
\hline
\end{tabular}

Keywords: Tomography, optical coherence/standards; Nerve fiber/ultrastructure; Retina/ ultrastructure; Optic atrophy/diagnosis; Case-control studies

\section{INTRODUCTION}

Optical coherence tomography (OCT) uses near-infrared light to produce images of the retinal structures from which estimates of thickness of the retinal layers can be made ${ }^{(1)}$. The ability of OCT to provide measurements of the retinal nerve fibre layer (RNFL) has been evaluated by several studies ${ }^{(2-7)}$. We recently demonstrated that OCT is able to detect RNFL loss in patients with optic chiasm lesions ${ }^{(8-10)}$. In these patients, the crossed nerve fibers originating in the nasal hemiretina are lost, with preservation of the uncrossed fibers, which originate in the temporal hemiretina and penetrate the optic nerve through the superior and inferior arcuate fiber bundles. The- 
refore, RNFL loss occurs predominantly on the nasal and temporal sides of the optic disc, a pattern identified as band atrophy (BA) of the optic nerve.

By studying eyes with BA, we documented that OCT is superior to scanning laser polarimetry at identifying RNFL loss in the temporal and nasal quadrants ${ }^{(11-13)}$. We also found that the fast Stratus-OCT scan protocol, with 256 scan points, has significantly improved the discrimination ability of OCT when compared to the earlier version of the equipment, with only 100 scan points ${ }^{(9)}$. Despite such improvements, average and quadrant measurements are still significantly more accurate than 30-degree segment analyses, presumably because of the small number of A scans in the segments.

The built-in signal analysis software of the latest OCT model (Stratus-OCT; Carl Zeiss Meditec) features two scanning protocols for RNFL measurement: (1) Fast RNFL thickness $(3.4 \mathrm{~mm}) \mathrm{scan}$, with a resolution of 256 scan points, and (2) regular RNFL thickness $(3.4 \mathrm{~mm}$ ) scan, with a resolution of 512 scan points. So far most studies have been performed with the fast RNFL protocol and only a few have compared the two scanning protocols ${ }^{(14-15)}$. The purpose of this study was to compare RNFL thickness as measured with the OCT fast and regular scanning protocols in eyes with BA and in normal controls. Also, the two protocols were compared with regard to their ability to detect patients with BA.

\section{METHODS}

This was a prospective, cross-sectional study, performed between March 2006 and February 2007. Approval from the Institutional Ethics Committee was obtained for the study.

A total of 29 eyes from 29 patients with temporal VF defect from chiasmal compression and 30 eyes from 30 normal controls were studied. All patients had already been submitted to previous treatment of the suprasellar lesion and had stable VF defects and visual acuity (VA) for at least 1 year prior to study entry.

All subjects underwent a complete ophthalmologic examination including VF with standard automated perimetry (SAP) using the 24-2 SITA-Standard strategy (Humphrey Field Analyzer, Carl-Zeiss Meditec). VF and OCT examinations were performed on the same day or within a maximum period of 2 weeks.

Inclusion criteria were best corrected VA of 20/30 or better in the study eye, spherical refraction within $\pm 5 \mathrm{D}$ and cylinder refraction within $\pm 3 \mathrm{D}$, intraocular pressure less than $22 \mathrm{mmHg}$ and reliable VF (defined as one with fewer than $25 \%$ fixation losses, false-positive responses or false-negative responses). Patients with previous history of intraocular pressure elevation, with clinical signs of glaucomatous optic neuropathy or optic disc anomaly were excluded.

Patients with BA were required to have complete or partial temporal hemianopia and a nasal hemifield within normal limits. A normal nasal hemifield was defined as the absence of any cluster of at least 3 points with $p<5 \%$ on the pattern deviation plot. Only one eye of each patient was selected for analysis.
The severity of VF defect in patients with BA was evaluated by calculating the temporal mean defect (TMD), by averaging the values of the total deviation plot for the 22 temporal points of the SAP test, excluding the 2 points immediately above and below the blind spot.

The control group consisted of healthy volunteers, from among the hospital staff. All had normal ophthalmic findings and SAP VF, defined as a pattern standard deviation (PSD) within the $95 \%$ confidence limit and a glaucoma hemifield test result within normal limits. Control eyes had healthy-looking optic discs.

Subjects underwent ocular imaging with dilated pupils using a commercially available Stratus-OCT, by an experienced examiner. Good-quality scans featured focused images and signal strength equal to or higher than 7 as well as a centered ring around the optic disc for RNFL scans.

The fast RNFL scan protocol consists of 3 consecutive $360^{\circ}$ scans with a diameter of $3.4 \mathrm{~mm}$ centered on the optic nerve head, each composed of $256 \mathrm{~A}$-scans taken in a single session of 1.92 seconds. The regular RNFL scan protocol differs from the fast protocol in that it is composed of 3 separate $360^{\circ}$ circular scans, each containing $512 \mathrm{~A}$-scans and obtained in 1.28 seconds, taking a total time of 3.84 seconds to acquire the entire set of 3 scans.

The RNFL thickness parameters calculated by the StratusOCT software (version 4.0.1) were average thickness $\left(360^{\circ}\right.$ scan), temporal quadrant thickness $\left(316^{\circ}-45^{\circ}\right)$, superior quadrant thickness $\left(46^{\circ}-135^{\circ}\right)$, nasal quadrant thickness $\left(136^{\circ}\right.$ $\left.225^{\circ}\right)$, inferior quadrant thickness $\left(226^{\circ}-315^{\circ}\right)$ and thickness for each of the twelve 30-degree segments, indicated as clockhour positions with the 3 o'clock position as nasal, 6 o'clock position as inferior, 9 o'clock position as temporal, and 12 o'clock position as superior.

RNFL values obtained with both protocols were compared using the paired $t$ test. Scan thickness values of eyes with BA and normal controls were compared using Student's $t$ test. Receiver operating characteristic (ROC) curves were calculated. A previously described method ${ }^{(16)}$ was used to compare areas under the ROC curves (AUCs). A $p$ value of less than 0.05 was considered statistically significant.

\section{RESULTS}

A total of 29 eyes with temporal hemianopia and 30 control eyes were studied. Twenty-seven patients had pituitary adenoma and 2 craniopharyngioma. The mean \pm standard deviation (SD) age was $43.2 \pm 14.0$ years (range 13-75) in BA patients, and $36.2 \pm 12.2$ years (range 20-69) in normals ( $p=0.1$; Student's $t$ test). Median (first quartile, third quartile) SAP mean deviation and SAP TMD were $-13.0 \mathrm{~dB}(-14.23 \mathrm{~dB},-7.56$ $\mathrm{dB})$ and $-23.95 \mathrm{~dB}(-28.77 \mathrm{~dB},-7.63 \mathrm{~dB})$, respectively.

In eyes with BA, peripapillary RNFL thickness (mean \pm SD, in $\mu \mathrm{m}$ ) was $78.53 \pm 23.59,37.37 \pm 7.12,87.83 \pm 15.92$ and $41.96 \pm 11.16$ in the superior, temporal, inferior and nasal qua- 
536 Comparison of retinal nerve fiber layer measurements using Stratus OCT fast and regular scan protocols in eyes with band atrophy of the optic nerve and normal controls

drants, respectively, when using the fast protocol. The mean global RNFL thickness was $61.47 \pm 10.82$. The corresponding figures for the regular protocol were $75.40 \pm 21.89,38.13 \pm 10.00$, $82.13 \pm 17.25$ and $43.17 \pm 8.23$. The mean global RNFL thickness was $60.07 \pm 9.85$. Thickness in the superior and inferior quadrants and in the 6 and 11 o'clock segments were significantly smaller, and in the 3 o'clock segment significantly greater, when using the regular scanning protocol (Table 1, Figure 1).

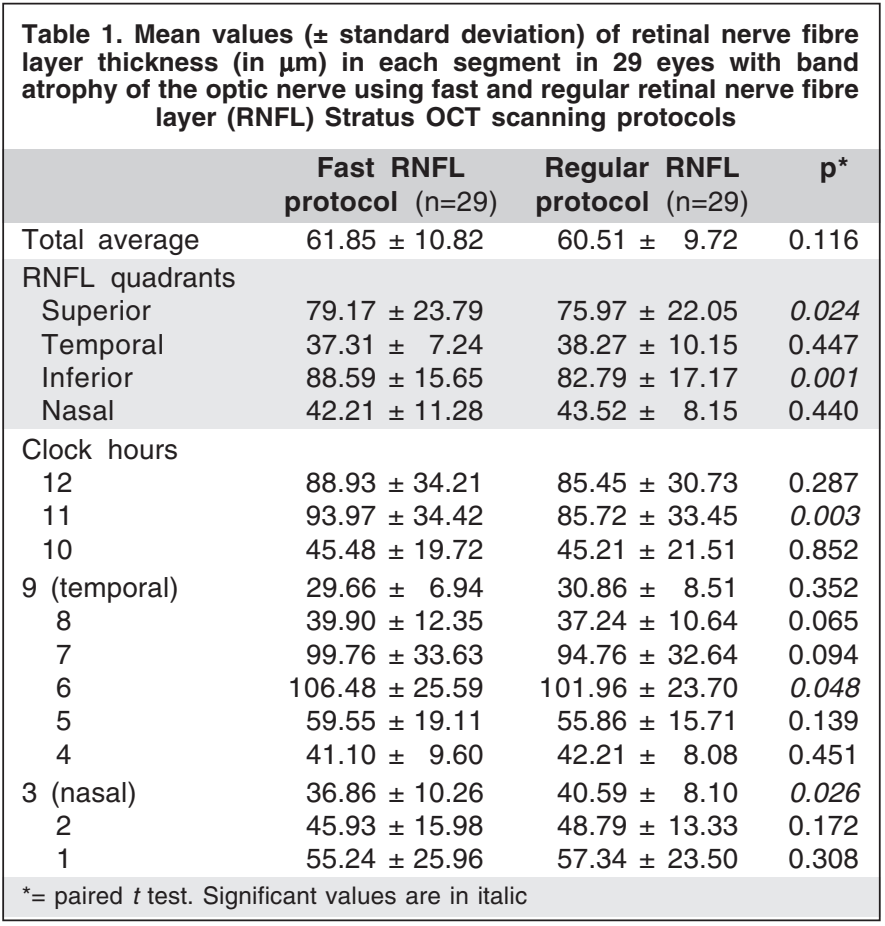

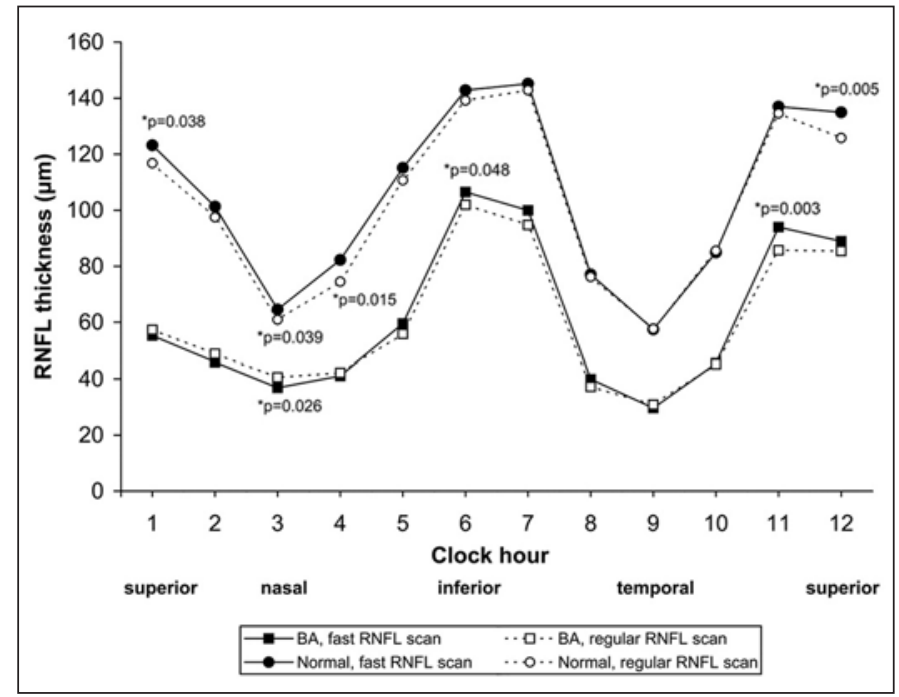

Figure 1 - Plotting of the mean retinal nerve fiber layer (RNFL) thickness per 30-degree segment along the optic disc circumference (indicated as clock hours) in normal eyes (above) and eyes with band atrophy (BA) of the optic nerve (below) both with the fast (black circle and square, continuous line) and the regular (empty circle and square, dashed line) RNFL protocols
In normal eyes, RNFL thickness (mean $\pm \mathrm{SD}$, in $\mu \mathrm{m}$ ) was $131.77 \pm 19.02,74.50 \pm 12.73,134.37 \pm 18.90$ and $80.40 \pm 13.79$ in the superior, temporal, inferior and nasal quadrants, respectively, measured with the fast protocol. The mean global RNFL was $107.89 \pm 17.80$. The corresponding figures for the regular protocol were $125.53 \pm 19.66,73.47 \pm 11.98,131.00 \pm 20.74$ and $77.47 \pm 14.07$. The mean global RNFL was $101.78 \pm 11.90$. Total average and superior and inferior quadrant measurements were significantly smaller with the regular protocol. RNFL measurements of the 30-degree segments were generally smaller with the regular protocol, but differences were significant only for segments corresponding to the 1, 3, 4 and 12 o'clock meridian (Table 2, Figure 1).

Fast and regular protocol values were significantly smaller $(p<0.001)$ in eyes with BA than in normal eyes with regard to total average, all four quadrants and all twelve 30-degree segments. There was no significant difference between the AUCs produced with the two protocols regardless of the considered parameter (Table 3).

\section{DISCUSSION}

The current study showed that the RNFL was reduced not only in the nasal and temporal quadrants but also in the superior and inferior segments of the optic disc of eyes with BA. This is in agreement with Midelberg and Yidegiligne' ${ }^{(17)}$ quantitative histological analysis of a patient with BA, who documented that, although the loss of RNFL in eyes with BA occurs predominantly in the nasal and temporal segments, the superior and inferior quadrants lost approximately $50 \%$ of

\begin{tabular}{|c|c|c|c|}
\hline & $\begin{array}{c}\text { Fast RNFL } \\
\text { protocol }(n=30)\end{array}$ & $\begin{array}{l}\text { Regular RNFL } \\
\text { protocol }(n=30)\end{array}$ & $p^{*}$ \\
\hline Total average & $107.89 \pm 17.80$ & $101.78 \pm 11.90$ & 0.020 \\
\hline \multicolumn{4}{|c|}{ RNFL quadrants } \\
\hline Superior & $131.77 \pm 19.02$ & $125.53 \pm 19.66$ & 0.005 \\
\hline Temporal & $74.50 \pm 12.73$ & $73.47 \pm 11.98$ & 0.416 \\
\hline Inferior & $134.37 \pm 18.90$ & $131.00 \pm 20.71$ & 0.044 \\
\hline Nasal & $80.40 \pm 13.79$ & $77.47 \pm 14.07$ & 0.125 \\
\hline \multicolumn{4}{|l|}{ Clock hours } \\
\hline 12 & $134.97 \pm 20.02$ & $125.80 \pm 24.60$ & 0.005 \\
\hline 11 & $137.00 \pm 24.36$ & $134.57 \pm 23.50$ & 0.214 \\
\hline 10 & $84.93 \pm 18.45$ & $85.56 \pm 16.56$ & 0.730 \\
\hline 9 (temporal) & $57.47 \pm 8.16$ & $57.66 \pm 8.45$ & 0.803 \\
\hline 8 & $77.07 \pm 16.80$ & $76.17 \pm 16.09$ & 0.660 \\
\hline 7 & $145.17 \pm 30.57$ & $142.83 \pm 26.59$ & 0.414 \\
\hline 6 & $142.83 \pm 26.24$ & $139.17 \pm 28.16$ & 0.198 \\
\hline 5 & $115.10 \pm 17.47$ & $110.70 \pm 22.91$ & 0.227 \\
\hline 4 & $82.27 \pm 16.62$ & $74.47 \pm 17.76$ & 0.015 \\
\hline 3 (nasal) & $64.57 \pm 14.05$ & $60.93 \pm 14.10$ & 0.039 \\
\hline 2 & $101.30 \pm 16.68$ & $97.50 \pm 18.63$ & 0.198 \\
\hline 1 & $123.20 \pm 24.76$ & $116.77 \pm 24.56$ & 0.038 \\
\hline
\end{tabular}




\begin{tabular}{|c|c|c|c|c|}
\hline $\begin{array}{l}\text { Fast protocol OCT } \\
\text { RNFL thickness parameters }\end{array}$ & AUC & $\begin{array}{c}\text { Regular protocol OCT } \\
\text { RNFL thickness parameters }\end{array}$ & AUC & $p^{*}$ \\
\hline Average thickness & 0.995 & Average thickness & 0.991 & 0.411 \\
\hline Superior thickness & 0.939 & Superior thickness & 0.949 & 0.340 \\
\hline Temporal thickness & 0.997 & Temporal thickness & 0.986 & 0.224 \\
\hline Inferior thickness & 0.961 & Inferior thickness & 0.961 & 1.000 \\
\hline Nasal thickness & 0.982 & Nasal thickness & 0.979 & 0.828 \\
\hline Thickness at 12 o'clock & 0.856 & Thickness at 12 o'clock & 0.856 & 1.000 \\
\hline Thickness at 11 o'clock & 0.837 & Thickness at 11 o'clock & 0.873 & 0.190 \\
\hline Thickness at 10 o'clock & 0.918 & Thickness at 10 o'clock & 0.919 & 0.955 \\
\hline Thickness at 9 o'clock & 0.997 & Thickness at 9 o'clock & 0.984 & 0.256 \\
\hline Thickness at 8 o'clock & 0.958 & Thickness at 8 o'clock & 0.971 & 0.388 \\
\hline Thickness at 7 o'clock & 0.856 & Thickness at 7 o'clock & 0.868 & 0.659 \\
\hline Thickness at 6 o'clock & 0.854 & Thickness at 6 o'clock & 0.856 & 0.943 \\
\hline Thickness at 5 o'clock & 0.978 & Thickness at 5 o'clock & 0.957 & 0.537 \\
\hline Thickness at 4 o'clock & 0.985 & Thickness at 4 o'clock & 0.932 & 0.141 \\
\hline Thickness at 3 o'clock & 0.949 & Thickness at 3 o'clock & 0.889 & 0.054 \\
\hline Thickness at 2 o'clock & 0.993 & Thickness at 2 o'clock & 0.982 & 0.317 \\
\hline Thickness at 1 o'clock & 0.957 & Thickness at 1 o'clock & 0.950 & 0.531 \\
\hline
\end{tabular}

their fibers, since ganglion cell axons originating from the nasal retina also penetrate the superior and inferior portions of the disc ${ }^{(17)}$.

Few studies have compared Stratus-OCT scans performed with the fast and the regular protocol. Investigators ${ }^{(14)}$ studied 61 glaucoma eyes (31 with and 30 without VF defects), using both scanning protocols. They found that in eyes with VF defects there was no significant difference in average RNFL thickness while in eyes without VF defects (therefore with greater RNFL thickness) the average RNFL thickness was significantly greater when using the fast scanning protocol. Values from quadrants and 30-degree segments were not reported. Other authors ${ }^{(15)}$, on the other hand, studied 182 subjects including normal eyes, glaucoma and glaucoma suspect eyes and found that the average RNFL thickness measurements in all population groups were significantly greater when using the fast protocol. The authors also observed that when comparing healthy subjects and glaucoma patients, the regular RNFL scan produced the largest area under the ROC curve (0.912) based on average RNFL thickness measurements.

The current study confirms that the fast RNFL scanning protocol tends to produce greater values in most measurements when compared to the regular scanning protocol. Our study, however, emphasizes that the tendency to overestimate RNFL thickness with the fast protocol is more pronounced in areas with thicker RNFL. For example, in normal eyes RNFL values were greater in all measurements except those of the 30degree segments located in the temporal area, a finding already reported by other authors ${ }^{(15)}$. Although those authors stressed the significantly greater values obtained with the fast protocol in most parameters, no statistically significant difference was observed in the comparisons corresponding to the 30-degree segments located in the thinner temporal area $\left(8,9\right.$ and 10 o'clock segments) in glaucoma and normal eyes ${ }^{(16)}$.

The difference in measuring ability observed between thick and thin RNFL areas with the two protocols became much more striking when we evaluated eyes with BA. In this condition RNFL thickness is reduced especially in the already thin areas located in the nasal and temporal quadrants of the optic disc. While our study is very similar to that of a previous study ${ }^{(15)}$ with regard to normal eyes, in eyes with BA we observed that the fast scanning protocol yielded significantly greater values in the (thicker) superior and inferior quadrants but smaller (although not statistically significant) values in the (thinner) nasal and temporal quadrants (Table 1). A similar tendency was observed in the 30-degree segment analysis. Measurements with the fast protocol were generally greater in thicker segments located superiorly and inferiorly and smaller in segments located nasally and temporally (Figure 1). Although not all comparisons yielded significant differences, the greater values of the fast protocol attained statistical significance difference in the segments corresponding to the 11 and 6 o'clock meridians. On the other hand, thickness values from the 3 o'clock meridian were significantly smaller with the fast than with the regular scanning protocol (Table 1). Thus, our study shows that the tendency to produce greater measurements in normal eyes and to some extent in eyes with reduced RNFL is not uniform but appears to be dependent on RNFL thickness: compared to the regular scanning protocol, the fast protocol tends to produce greater values in areas with thick RNFL and similar or even smaller values in areas with thin RNFL (Tables 1 and 2, Figure 1).

Since the difference in measurements between the two scanning protocols varied according to disc sector, it is pro- 
bably not due to intrinsic systematic error in the equipment. Some investigators ${ }^{(15)}$ pointed out that as the estimation of RNFL thickness is based on the reflectivity signal generated by the scanner, the difference observed may be related to the reduced signal density of the lower-resolution image generated by the fast scan. A reduced signal density may lower the threshold set for the posterior boundary of RNFL and thus result in increased thickness in RNFL measurements. To explain the lack of difference in measurements observed in temporal segments in their study, some authors ${ }^{(15)}$ suggested that the effect of reduced signal density was probably minimal in areas with thin RNFL. Our findings take this conclusion one step further indicating that the fast protocol tends to overestimate thickness in areas with thick RNFL and underestimate values in areas with thin RNFL; however, further studies are necessary to clarify these relationships.

More than comparing the values from the two scanning protocols the purpose of our study was to investigate whether increasing the number of scans would result in greater discrimination ability between eyes with BA and controls. Thus, based on the absence of significant differences between the AUCs of the two scanning protocols, our findings indicate that the protocols are equally efficient at differentiating eyes with BA from normal controls (Table 3 ). This finding differs from the conclusion of other authors ${ }^{(15)}$ who found the regular protocol to have a greater discrimination ability in patients with glaucoma and glaucoma suspects. We believe that the differences in the profile of the study population may explain the difference in conclusion between the two studies. Since the fast protocol tends to produce greater values in areas with thick RNFL and smaller values in areas with thin RNFL, which are particularly affected in eyes with $\mathrm{BA}$, it is possible that the AUCs observed with the fast scanning protocol were artifactually increased in our study, resulting in a better performance of the fast protocol than that observed by a previous study ${ }^{(15)}$. The disagreement may also be due to differences in the amount of RNFL loss in the studied diseases. RNFL loss often varies more among glaucomatous eyes than among the eyes with severe BA of the optic nerve, as evaluated in our study. In fact, the standard deviation of our average RNFL measurements in eyes with BA was lower (approximately $10 \mu \mathrm{m}$ ) than that of the glaucomatous eyes studied by others ${ }^{(15)}$ (approximately $20 \mu \mathrm{m}$ ). Thus, the greater number of points (512) in the regular scan protocol could make it a better tool than the fast scan protocol to distinguish normal eyes from glaucomatous eyes with early damage characterized by slight RNFL reduction but not necessarily to distinguish normal eyes from eyes with severe BA of the optic nerve such as those from our study. Further studies with glaucoma patients and with other patterns of RNFL loss are therefore necessary to define which scanning protocol provides the greatest discrimination ability when compared to normal eyes.

In conclusion, our study shows that RNFL measurements obtained with the fast scanning protocol tend to be greater in areas with thick RNFL and smaller in areas with thin RNFL as compared to measurements obtained with the regular scanning protocol. Although the two OCT protocols were equally efficient at differentiating eyes with BA from normal eyes, the values of RNFL thickness obtained by the two instruments were generally different. Investigators and clinicians should be aware of this fact when comparing RNFL measurements obtained with the fast and regular scanning protocols of the same equipment.

\section{RESUMO}

Objetivo: Comparar as medidas da camada de fibras nervosas da retina (CFNR) realizada com dois protocolos de exame da tomografia de coerência óptica (TCO) em olhos com atrofia em banda $(\mathrm{AB})$ do nervo óptico e controles. Métodos: Vinte nove olhos com $\mathrm{AB}$ e 30 olhos normais foram submetidos a TCO utilizando tanto o protocolo "fast" (256 scans A) como o "regular" (512 scans A). As medidas foram comparadas. Resultados: Em olhos com AB, as medidas da CFNR com o protocolo "fast" foram significativamente maiores do que aquelas do protocolo "regular" nos quadrantes superior e inferior e significativamente menores nos segmentos de 30 graus localizados nos meridianos correspondentes às 3 e 6 horas. Nos olhos normais, as medidas com o protocolo "fast" correspondentes à média global, aos quadrantes superior e inferior e aos segmentos de 30 graus correspondentes aos meridianos situados à $1,3,4$ e 12 horas foram significativamente maiores do que aquelas do protocolo "regular". As medidas com os dois protocolos foram significativamente diferentes em olhos com AB quando comparados aos olhos normais. Conclusões: Embora as medidas obtidas tanto com o protocolo "fast" como com o "regular" tenha sido igualmente eficientes na diferenciação de olhos com $\mathrm{AB}$ dos normais, o protocolo "fast" forneceu valores maiores em áreas com CFNR mais espessas, e menores em áreas com CFNR mais finas quando comparados com o protocolo "regular". Deve-se estar atento a estas diferenças quando se comparam as medidas obtidas com os dois protocolos de exame.

Descritores: Tomografia de coerência óptica/padronização; Fibras nervosas/ultraestrutura; Retina/ultraestrutura; Atrofia óptica/diagnóstico; Estudos de casos e controles

\section{REFERENCES}

1. Huang D, Swanson EA, Lin CP, Schuman JS, Stinson WG, Chang W, et al. Optical coherence tomography. Science. 1991;254(5035):1178-81.

2. Schuman JS, Pedut-Kloizman T, Hertzmark E, Hee MR, Wilkins JR, Coker JG, et al. Reproducibility of nerve fiber layer thickness measurements using optical coherence tomography. Ophthalmology. 1996;103(11):1889-98.

3. Baumann M, Gentile RC, Liebmann JM, Ritch R. Reproducibility of retinal thickness measurements in normal eyes using optical coherence tomography. Ophthalmic Surg Lasers. 1998;29(4):280-5.

4. Blumenthal EZ, Williams JM, Weinreb RN, Girkin CA, Berry CC, Zangwill LM. Reproducibility of nerve fiber layer thickness measurements by use of optical coherence tomography. Ophthalmology. 2000;107(12):2278-82. 
5. Jones AL, Sheen NJ, North RV, Morgan JE. The Humphrey optical coherence tomography scanner: quantitative analysis and reproducibility study of the normal human retinal nerve fibre layer. Br J Ophthalmol. 2001;85(6):673-7.

6. Villain MA, Greenfield DS. Peripapillary nerve fiber layer thickness measurement reproducibility using optical coherence tomography. Ophthalmic Surg Lasers Imaging. 2003;34(1):33-7.

7. Medeiros FA, Zangwill LM, Bowd C, Weinreb RN. Comparison of the GDx VCC scanning laser polarimeter, HRT II confocal scanning laser ophthalmoscope, and stratus OCT optical coherence tomograph for the detection of glaucoma. Arch Ophthalmol. 2004;122(6):827-37.

8. Monteiro ML, Leal BC, Rosa AA, Bronstein MD. Optical coherence tomography analysis of axonal loss in band atrophy of the optic nerve. Br J Ophthalmol. 2004;88(7):896-9.

9. Monteiro ML, Leal BC, Moura FC, Vessani RM, Medeiros FA. Comparison of retinal nerve fibre layer measurements using optical coherence tomography versions 1 and 3 in eyes with band atrophy of the optic nerve and normal controls. Eye. 2007;21(1):16-22.

10. Moura FC, Medeiros FA, Monteiro ML. Evaluation of macular thickness measurements for detection of band atrophy of the optic nerve using optical coherence tomography. Ophthalmology. 2007;114(1):175-81.

11. Monteiro ML, Medeiros FA, Ostroscki MR. Quantitative analysis of axonal loss in band atrophy of the optic nerve using scanning laser polarimetry. $\mathrm{Br}$ J Ophthalmol. 2003;87(1):32-7.

12. Leal BC, Moura FC, Monteiro ML. Comparação entre o polarímetro de varredura a laser, a tomografia de coerência óptica 1 e o Stratus-oct na detecção da perda axonal da atrofia em banda do nervo óptico. Arq Bras Oftalmol. 2006; 69(4):531-7.

13. Monteiro ML, Moura FC. Comparison of the GDx VCC scanning laser polarimeter and the stratus optical coherence tomograph in the detection of band atrophy of the optic nerve. Eye. 2008;22(5):641-8.

14. Zafar S, Gurses-Ozden R, Makornwattana M, Vessani R, Liebmann JM, Tello C, Ritch R. Scanning protocol choice affects optical coherence tomography (OCT-3) measurements. J Glaucoma. 2004;13(2):142-4.

15. Leung CK, Yung WH, Ng AC, Woo J, Tsang MK, Tse KK. Evaluation of scanning resolution on retinal nerve fiber layer measurement using optical coherence tomography in normal and glaucomatous eyes. J Glaucoma. 2004; 13(6):479-85.

16. DeLong ER, DeLong DM, Clarke-Pearson DL. Comparing the areas under two or more correlated receiver operating characteristic curves: a nonparametric approach. Biometrics. 1988;44(3):837-45.

17. Mikelberg FS, Yidegiligne HM. Axonal loss in band atrophy of the optic nerve in craniopharyngioma: a quantitative analysis. Can J Ophthalmol. 1993;28(2):69-71. 